\title{
Multi-year assessment of variability in spatial and social relationships in a subterranean rodent, the highland tuco-tuco (Ctenomys opimus)
}

\author{
Shannon L. O'Brien ${ }^{1} \cdot$ Mauro N. Tammone ${ }^{2}$ Pablo A. Cuello ${ }^{3}$ Eileen A. Lacey ${ }^{1}$ \\ Received: 10 December 2020 / Revised: 27 April 2021 / Accepted: 3 May 2021 / Published online: 25 May 2021 \\ (c) The Author(s) 2021
}

\begin{abstract}
In some species, populations routinely contain a mixture of lone and group-living individuals. Such facultative sociality may reflect individual differences in behavior as well as adaptive responses to variation in local environmental conditions. To explore interactions between individual- and population-level variabilities in behavior in a species provisionally described as facultatively social, we examined spatial and social relationships within a population of highland tuco-tucos (Ctenomys opimus) at Laguna de los Pozuelos, Jujuy Province, Argentina. Using data collected over 5 consecutive years, we sought to (1) confirm the regular occurrence of both lone and group-living individuals and (2) characterize the temporal consistency of individual social relationships. Our analyses revealed that although the study population typically contained lone as well as group-living animals, individual spatial and social relationships varied markedly over time. Specifically, the extent to which individuals remained resident in the same location across years varied, as did the number of conspecifics with which an animal lived, with an overall tendency for individuals to live in larger groups over successive years. Collectively, these analyses indicate that population-level patterns of behavior in C. opimus are consistent with facultative sociality but that this variation does not arise due to persistent differences in individual behavior (i.e., living alone versus with conspecifics). Instead, based on changes in spatial and social relationships across years, we suggest that variation in the tendency to live in groups is shaped primarily by local ecological and demographic conditions.
\end{abstract}

\section{Significance statement}

Characterizing variation in conspecific relationships is critical to understanding the adaptive bases for social behavior. Using data collected over 5 successive years, we examined temporal variation in spatial and social relationships within a population of highland tuco-tucos (C. opimus) from northern Argentina. In addition to providing the first multi-year assessment of the behavior and demography of this species, our analyses generate important insights into relationships between individual behavior and population-level patterns of social organization. The behavioral variability evident in our study population suggests that $C$. opimus is an ideal system in which to explore the causes and consequences of individual differences in social behavior.

Keywords Behavior $\cdot$ Ctenomyidae $\cdot$ Facultative sociality $\cdot$ Home range $\cdot$ Space use $\cdot$ Subterranean

Communicated by E. Korpimäki

Shannon L. O’Brien

slobrien@berkeley.edu

1 Museum of Vertebrate Zoology and Department of Integrative Biology, University of California, Berkeley, CA 94720 , USA

2 INIBIOMA-CONICET and Programa de Estudios Aplicados a La Conservación del Parque Nacional Nahuel Huapi (CENAC-PHHN, CONICET), 8400 S. C. de Bariloche, Rio Negro, Argentina

3 Instituto Argentino de Investigaciones de Zonas Aridas (IADIZA-CCT CONICET), Av. Ruiz Leal s/n, Parque General San Martin, 5500 Mendoza, Argentina

\section{Introduction}

Understanding the adaptive bases for differences in social relationships is a fundamental goal of behavioral research. In some species, these differences include the occurrence of both lone and group-living individuals within a population. Such variation - often referred to as facultative socialityhas been reported for numerous taxa, including mammals (Le Roux et al. 2009; Eason 2010; Blumstein 2013; Smith et al. 2016), birds (Öst et al. 2015), reptiles (Riley et al. 2018), fish (Soria et al. 2007), and insects (May-Itzá et al. 2014; Shell and Rehan 2017; Smith et al. 2018). Despite 
widespread use of this term, the definition of facultative sociality remains unclear. For example, facultative sociality has been used to describe adaptive variation in current social organization (Rabosky et al. 2012; Öst et al. 2015) as well as to imply an evolutionary progression from solitary to group life (Rehan et al. 2010; Shell and Rehan 2018). As part of distinguishing between these fundamentally different interpretations, it is necessary to understand the nature of intraspecific differences in social behavior. In terms of current adaptive function, facultative variation in social relationships should be temporally persistent, meaning that this variation occurs across multiple seasons or years as individuals respond to omnipresent short-term fluctuations in ecological or demographic conditions. Accordingly, a critical step in characterizing a population as facultatively social is to demonstrate that it regularly contains a mixture of solitary and group-living individuals.

Population-level variation in social relationships results from the behavior of individuals. In facultatively social populations, lone versus group-living animals may arise for several reasons (Cahan et al. 1999). For example, individuals may vary in their tendency to associate with conspecifics (Lott 1984, 1991), resulting in some animals that consistently live alone while others consistently live in groups, regardless of ecological or demographic conditions. Variation in social relationships may also occur if individuals alter their behavior to better capitalize on the relative fitness benefits of different social options (Rehan et al. 2014; Ortiz et al. 2019). Finally, variation in social relationships may reflect stochastic demographic factors such as recruitment or mortality, each of which may influence the number of conspecifics with which an individual lives (Blumstein 2013; Hatchwell et al. 2013). Although these scenarios are not mutually exclusive, they generate distinct expectations regarding the temporal patterning of social relationships. Specifically, the first predicts that an individual's behavior should remain consistent over time. In contrast, the second predicts that individual behavior will change; if one social option (e.g., living in a group) consistently yields higher fitness benefits (Hayes and Solomon 2004; Lacey 2004; Blumstein et al. 2018) then such changes may be directional, reflecting the tendency for all individuals to move toward the same best fitness outcome. The third scenario predicts that changes in social environment will not display any consistent directionality. Although facultative sociality likely reflects the complex interplay of one or more of these sources of behavioral variation, these predictions provide a useful framework for exploring relationships between individual- and population-level patterns of behavior.

One mammal that has been described as facultatively social is the highland tuco-tuco (Ctenomys opimus). This subterranean species of rodent occurs in high-elevation habitats in Argentina, Bolivia, and Peru (Patton et al. 2015).
To date, the only behavioral studies of $C$. opimus that have been conducted were completed in northern Argentina, where these diurnal animals inhabit open grassland areas on valley floors and along waterways. Unlike most other tuco-tucos, C. opimus spends a substantial proportion of time foraging above ground, with the result that individuals are fully visible while feeding on salt grass (genus Distichlis) and other high Andean vegetation. Both direct observations and analyses of radiotelemetry data indicate that members of the population of C. opimus at Laguna de los Pozuelos, Jujuy Province, Argentina, are group-living, with multiple adults (mean $=3.7 \pm 2.1 \mathrm{SD}$; range $=1-7$ ) of both sexes sharing burrow systems and subterranean nests ( $\mathrm{O}$ 'Brien et al. 2020). A social group may occupy several nest sites, resulting in variable combinations of group mates that share a nest on a given night (O'Brien et al. 2020). Importantly, these analyses have also revealed the presence of solitary individuals within this population, raising the possibility that C. opimus is facultatively social.

These findings were based on only a single season of fieldwork; and thus, O'Brien et al. (2020) were unable to determine if the observed variation in social behavior is temporally persistent, with a mixture of solitary and groupliving individuals present in the population in multiple years. For the same reason, these authors could not evaluate how individual patterns of behavior contribute to population-level differences in social relationships. To explore these aspects of the social organization of $C$. opimus and to determine if the behavior of these animals is consistent with definitions of facultative sociality based on current adaptive function, we documented spatial and social relationships among members of the population at Laguna de los Pozuelos across five consecutive years. Specifically, we sought to determine if (1) both lone and group-living animals were present during each year of the study and (2) individual patterns of behavior (e.g., lone versus group-living) remained consistent across years. While these analyses focus on the temporal consistency of individual behavior, they provide a critical foundation for future studies aimed at exploring the roles of ecological and demographic correlates of living alone versus within a group. In addition to providing the first longitudinal assessment of the social organization of C. opimus, our data generate important insights into interactions between individual- and population-level variabilities in social relationships in free-living animals.

\section{Methods}

\section{Study site}

The population of highland tuco-tucos (Ctenomys opimus) studied was located in Monumento Natural Laguna de los 
Pozuelos, Jujuy Province, Argentina $\left(22^{\circ} 34^{\prime} \mathrm{S}, 66^{\circ} 01^{\prime} \mathrm{W}\right.$; elevation: $3600 \mathrm{~m}$ ); this is the same population of $C$. opimus studied by O'Brien et al. (2020). The ca. 3-ha study site was located near the park entrance, along the western bank of the Río Cincel (Fig. 1). Data were collected between November and January during each year from 2010 to 2014 . The mean duration of each annual field effort was $14.6 \pm 4.8$ SD days $(\mathrm{N}=5$ years). All fieldwork was conducted during the late austral spring, which corresponds to the primary breeding season for the study population.

\section{Animal capture and marking}

Members of the study population were captured using tomahawk-style live traps baited with carrots (O'Brien et al. 2020). Open traps were placed at active burrow entrances, as identified by the presence of recently excavated soil and fresh fecal pellets as well as observations of animals using those entrances. Trapping was conducted during daylight hours; open traps were monitored continuously and animals were retrieved immediately upon capture. Alternatively, trap-averse individuals were captured by hand using a soft, elastic noose that had been placed around an active burrow entrance; this procedure is described in detail in Lacey et al. (1997). The location of each capture was recorded using a hand-held GPS unit (accuracy $\sim 6 \mathrm{~m}$ ). Additionally, we recorded each capture locality using a Cartesian coordinate system ( $8 \mathrm{~m} \times 8 \mathrm{~m}$ grid cells; Fig. 1$)$ that was (re)established on the study site each year prior to the start of trapping.

Upon first capture, each animal was marked for permanent identification with a uniquely coded PIT tag (IMI1000, Bio Medic Data Systems, Inc., Seaford, DE) that was inserted beneath the skin at the nape of the neck. PIT tags were read using a hand-held scanner (DAS 4000 Pocket Scanner, Bio Medic Data Systems Inc., Seaforth, DE). Each time that an animal was captured, its sex and body weight were recorded. Data on body weight and reproductive status were used to determine the age class (subadult or adult) of
Fig. 1 Map of the study site located at Laguna de los Pozuelos, Jujuy Province, Argentina. A representation of our $8 \mathrm{~m} \times 8 \mathrm{~m}$ grid system is included in the lower left of the study site outline. Included are photos of (a) the study site with grid flags and (b) a highland tuco-tuco (Ctenomys opimus)

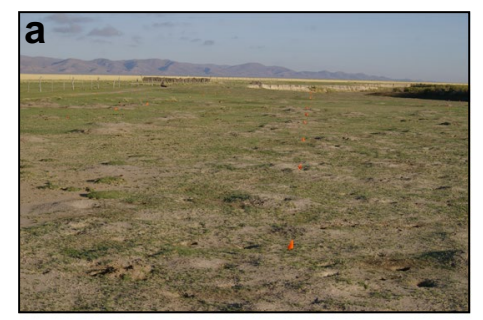

Study site at Laguna de los Pozuelos, Jujuy Province

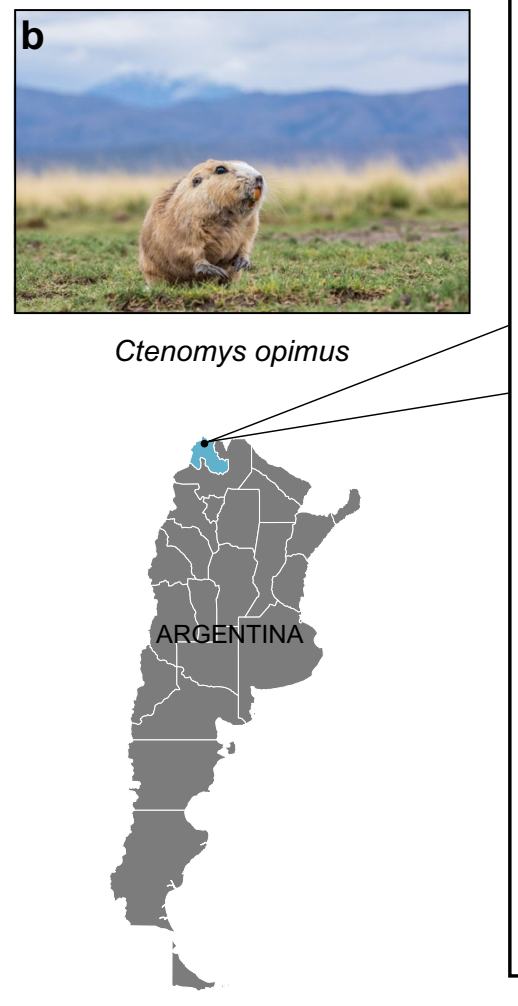

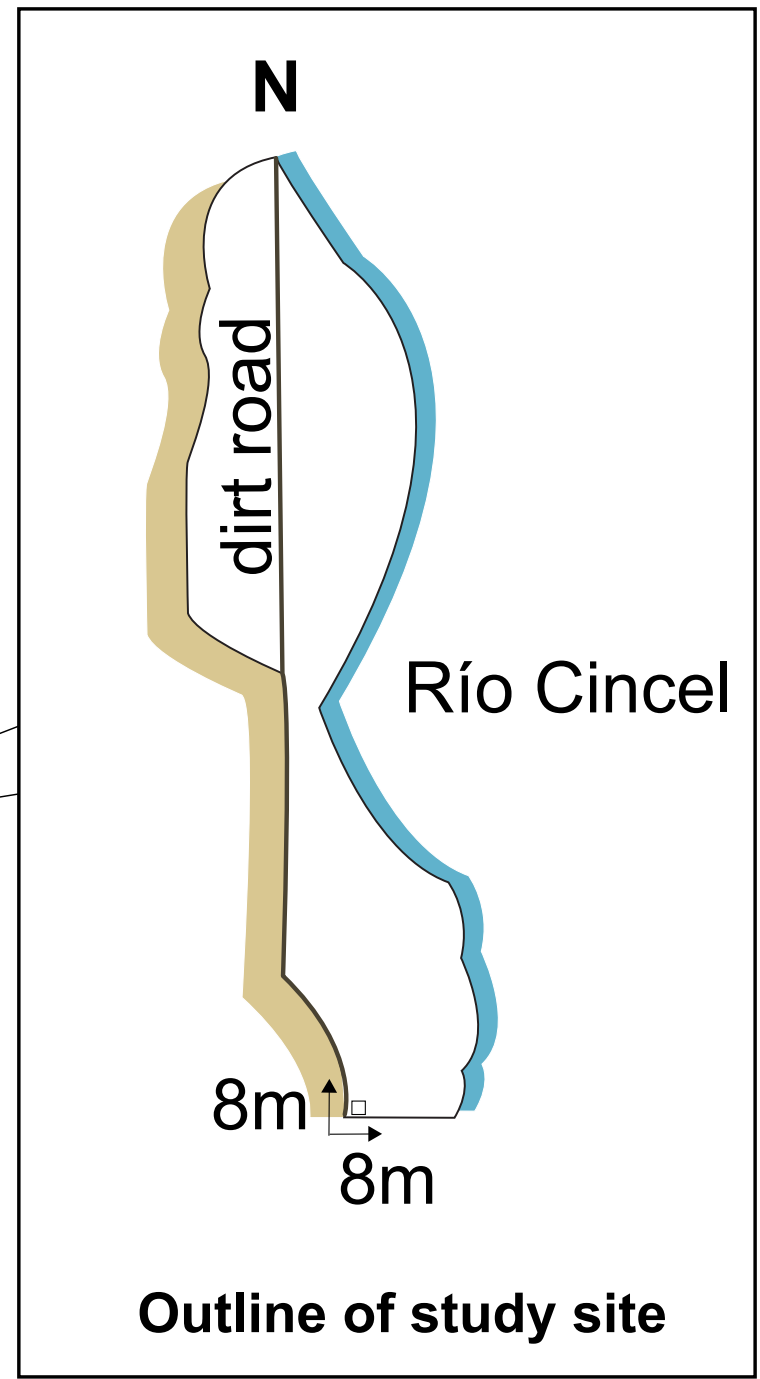


each individual during each field season. The reproductive status of adult females was assessed based on the appearance of the external genitalia (sexually receptive), the ability to palpate fetuses (pregnant), or the presence of enlarged mammae (lactating). Body weights for non-reproductive females were significantly less than those of reproductive individuals; and thus, non-reproductive females were classified as subadults (EAL et al., unpubl. data). In contrast, because the testes of males in the study population never descend externally, the reproductive status of these animals could not be determined based on external appearance. Instead, based on analyses of the distribution of male body weights within the population, individuals weighing less than $300 \mathrm{~g}$ were classified as subadults (EAL et al., unpubl. data). To facilitate visual observations of the study animals, human hair dyes (e.g., Manic Panic semi-permanent hair color cream) were used to mark the fur of each individual with a unique combination of colored patches, after which the animal was released at the location at which it had been captured.

\section{Scan sampling of animal locations}

Previous analyses of the study population revealed no significant differences between spatial and social relationships identified based on analyses of radio-telemetry data versus direct visual observations of animal locations (O'Brien et al. 2020). For simplicity, only visual observations were recorded during this study. A scan sampling protocol (Altmann 1974) was used to record the localities of all animals visible on the study site. Typically, the study site was divided into three sub-sections, each of which was monitored by a different observer stationed at a fixed location. Scans of each sub-section of the site were conducted simultaneously, with each observer visually searching their portion of the site following a standard pattern. It was not possible to record data blind because our study involved focal animals in the field. The locality of each animal detected was recorded to the nearest half meter using the $8 \mathrm{~m} \times 8 \mathrm{~m}$ grid system established on the study site (O'Brien et al. 2020); estimates of the locations of objects placed at known locations revealed this procedure to be accurate to within $<1 \mathrm{~m}$. Scans $(\sim 10$ min each) were completed multiple times per day with

Table 1 Summary of the data analyzed. For each year of the study, the number of animals of each sex is indicated, as are the dates of data collection, the mean $( \pm 1 \mathrm{SD})$ number of days during which data a minimum of $1 \mathrm{~h}$ between successive scans. Scan sampling was conducted during daylight hours (0700-2000 h) on most days of each field season.

\section{Spatial relationships}

Patterns of space use were analyzed using 95\% minimum convex polygons (MCPs) generated with the adehabitatHR package in R (Calenge 2015). MCPs are a commonly used method for visualizing the areas occupied by free-living animals (Harris et al. 1990). Although MCPs may overestimate home range size, exclusion of the $5 \%$ of data points that are most distant from an individual's centroid of activity (95\% MCPs) reduces this tendency and provides a generally robust procedure for determining if the areas used by different animals overlap, as expected in group-living species (Ebensperger et al. 2004; Sobrero et al. 2014). The minimum number of observations allowed per individual was 6 , which exceeds the minimum number of data points required by adehabitatHR to construct a home range (Calenge 2015); during each year of the study, most (>90\%) of the individuals for which $95 \%$ MCPs were constructed were characterized by $>10$ data points (Table 1). Given that home range sizes tended to increase until ca. 30 data points per individual were examined (O'Brien et al. 2020), use of fewer localities to characterize spatial relationships should have been conservative with respect to the size of the area used by an individual and thus the potential for spatial overlap with conspecifics. For animals captured during two or more years of the study, we examined the temporal consistency of patterns of space use by comparing estimates of home range size in successive years.

To characterize spatial relationships among members of the study population, we generated pairwise estimates of percent overlap between 95\% MCPs. Because overlap between pairs of animals may not have been symmetric, estimates were calculated from the perspective of each individual in a pair. Within years, percent overlap was calculated for all pairwise combinations of individuals for which $95 \%$ MCPs were available; these data formed the basis for social network analyses aimed at identifying distinct social units within the study population (see below). Between years, the

were collected per individual, and the mean $( \pm 1 \mathrm{SD})$ number of visual fixes recorded per individual. For means, the range of values is reported in parentheses

\begin{tabular}{lllrr}
\hline Year & Field season & \# of animals monitored & Mean \# days observed & Mean \# fixes recorded \\
\hline 2010 & $23 \mathrm{Dec}-9 \mathrm{Jan}$ & $8 \mathrm{M}, 29 \mathrm{~F}$ & $6.9 \pm 4.0(2-16)$ & $30.2 \pm 25.0(7-120)$ \\
2011 & $29 \mathrm{Nov}-18 \mathrm{Dec}$ & $16 \mathrm{M}, 24 \mathrm{~F}$ & $9.4 \pm 4.7(3-19)$ & $38.3 \pm 25.3(7-98)$ \\
2012 & $23 \mathrm{Nov}-9 \mathrm{Dec}$ & $27 \mathrm{M}, 43 \mathrm{~F}$ & $12.6 \pm 3.8(2-16)$ & $48.8 \pm 20.4(6-112)$ \\
2013 & $20 \mathrm{Nov}-29 \mathrm{Nov}$ & $4 \mathrm{M}, 6 \mathrm{~F}$ & $6.6 \pm 2.0(4-9)$ & $22.5 \pm 12.4(12-44)$ \\
2014 & $2 \mathrm{Dec}-18 \mathrm{Dec}$ & $16 \mathrm{M}, 11 \mathrm{~F}$ & $6.9 \pm 2.3(3-10)$ & $24.9 \pm 13.5(6-46)$ \\
\hline
\end{tabular}


consistency of home range locations was assessed by calculating pairwise estimates of percent overlap of an individual with itself; these estimates were generated for all animals present on the study site during two or more successive field seasons.

\section{Social network analyses}

To characterize social relationships among members of the study population, we used social network analyses (Wey et al. 2008; Krause et al. 2009) to identify the number of conspecifics with which each individual was associated during each year of the study. Specifically, pairwise measures of percent overlap between $95 \%$ MCPs were used to generate association matrices that were then analyzed in SOCPROG (Whitehead 2009) to identify hierarchical spatial clusters of individuals. The fit between association matrices and the resulting clusters was assessed using the cophenetic correlation coefficient, with values $\geq 0.8$ considered indicative of a strong correspondence between these datasets (Bridge 1993). Significant clusters of individuals were identified using the maximum modularity criterion, which provides a measure of the degree to which a population is divided into distinct spatial units; values $>0.3$ are generally interpreted as evidence of significant spatial clustering (Newman 2006; Whitehead 2008). To describe the results of these analyses, we use the term "social unit" to refer to any spatially distinct subset of animals identified by SOCPROG, including both lone and group-living individuals.

For individuals captured during two or more years of the study, we evaluated the temporal consistency of social relationships by examining the number of animals with which each individual was spatially associated (i.e., social unit size) during each year that they were present in the study population. We also examined annual changes in several of the social network metrics generated by SOCPROG (Whitehead 2009). The metrics examined were network strength (a measure of the sum of an individual's associations), eigenvector centrality (a measure of how well an individual is associated plus how well their associates are associated), affinity (a measure of the weighted average strength of an individual's associations), reach (a measure of how well an individual is indirectly connected to other individuals in the population), and the clustering coefficient for the network (a measure of how well an individual's associates are associated). Detailed descriptions of these parameters are provided in Whitehead (2009). To assess the consistency of social relationships across years, for all animals captured in two or more successive field seasons, we compared the identities of the animals with which they were associated (i.e., the other members of the social unit to which they were assigned) in one year to the identities of the animals with which they were associated in the following year.

\section{Statistical analyses}

All statistical tests were performed in R v. 3.5.0 (R Core Team 2013). For two-sample tests, normality of the data was assessed using Shapiro-Wilk's tests, after which parametric or non-parametric statistics were employed as appropriate. For animals monitored during two or more field seasons, we used linear models to identify predictors of home range size, social unit size, and the extent to which each individual overlapped spatially with itself in successive years. For each of these response variables, Q-Q plots were used to determine the underlying distribution that best fit the data obtained. Based on these analyses, models were constructed as follows:

1. Home range size. Linear mixed models based on a Gaussian distribution were used to identify predictors of home range size, with sex, age class (adult or subadult), and number of years $(1,2$, or 3$)$ on-site as fixed effects, and animal ID and year of data collection as random effects. Models were run with and without all possible interactions between predictor variables.

2. Social unit size. Generalized linear mixed models based on a Poisson distribution were used to examine predictors of social unit size. As with analyses of home range size, sex, age class (adult or subadult), and number of years $(1,2$, or 3$)$ on-site were included as fixed effects, and animal ID and year of data collection were included as random effects. Models were run with and without all possible interactions between predictor variables.

3. Overlap with self. Linear regressions based on a Gaussian distribution were conducted with sex and age class (adult or subadult) included as fixed effects. Overlap with self was determined based on comparisons of home ranges in either years 1 and 2 or years 2 and 3 that an individual was present on the study site. The model was run with and without all possible interactions among predictor variables.

The Akaike information criterion (AIC) was used to identify the best fit model for each response variable. When appropriate based on model outcomes, we used post hoc Tukey's honest significant differences (HSD) tests to determine if variation in our response variables was influenced by the number of years that an animal was on-site. Kruskal-Wallis tests and Dunn's post hoc tests were used to examine differences in social network metrics relative to the number of years that an animal was present on the study site. Throughout the text, means are reported \pm 1 SD. 


\section{Results}

A total of 208 (84 males, 124 females) highland tuco-tucos was captured during the course of this study. Review of trapping records and field notes indicated that the number of uncaught animals ranged from 1 to 4 per year, representing a mean of $7.6 \pm 5.5 \%$ of the individuals present on the site during each year of the study. Of the animals captured, 184 (88.5\%; 71 males, 113 females) were observed a sufficient number of times for analyses of spatial and social relationships. The number of animals for which sufficient data could not be obtained ranged from 0 to 5 per year, representing a mean of $4.5 \pm 3.6 \%$ of the individuals captured during each year of the study. Of the 184 animals for which home ranges were constructed, 27 (14.7\%; 20 males, 7 females) were subadults at the time of first capture. Flooding of the study area during December 2012 resulted in a marked reduction in the number of animals resident on the site during the 2013 field season; although this event reduced the sample sizes for some analyses, it did not preclude efforts to characterize variation in social relationships within or between years. For each year of the study, the dates of data collection, the number of animals monitored, the mean number of days per individual on which data were collected, and the mean number of visual fixes recorded per individual are given in Table 1.

\section{Annual variation in social unit size}

Social network analyses generated cophenetic correlation coefficients $>0.8$ (range $=0.84-0.97$ ) for all years of the study (Supplementary Fig. 1), indicating a strong correspondence between overlap of 95\% MCPs and the association indices generated by SOCPROG. Maximum modularity was $>0.43$ (range $=0.43-0.76$ ) in all years, suggesting significant spatial clustering of individuals within the study population. Based on the clusters of animals identified by these analyses (Supplementary Fig. 1), the study population contained a mix of lone and groupliving animals in four of the five years monitored; the sole exception was the 2012 field season, when only groupliving individuals were detected (Table 2). In all cases, lone individuals were adults; $4(66.7 \%)$ of the 6 lone individuals identified were females (Supplementary Fig. 1). Comparisons of home ranges for these animals with field notes and localities recorded for individuals for which home ranges could not be constructed indicated that in no case did putatively lone animals overlap with individuals not included in analyses of social unit size. The number of social units composed of $\geq 2$ animals ranged from 3 to 9 per year (mean $=5.2 \pm 1.8, N=5$ years). Social unit size (i.e., the number of individuals per social unit) varied
Table 2 Summary of spatial clustering of individuals within the study population. For each year of data collection, the number of lone animals, pairs ( 2 individuals), and groups $(3+$ individuals) revealed by social network analyses (Supplementary Fig. 1) are indicated, as is the total number of social units identified during that year. All social units included $\geq 1$ adult; no social units were composed only of subadults

\begin{tabular}{lllll}
\hline Year & \multicolumn{2}{l}{ Social unit size } & \\
\cline { 2 - 5 } & Lone & Pairs & Groups & $\begin{array}{l}\text { Total } \\
\text { \#social } \\
\text { units }\end{array}$ \\
\hline 2010 & 2 & 0 & 4 & $\mathbf{6}$ \\
2011 & 2 & 0 & 7 & $\mathbf{9}$ \\
2012 & 0 & 0 & 5 & $\mathbf{5}$ \\
2013 & 1 & 2 & 1 & $\mathbf{4}$ \\
2014 & 1 & 5 & 4 & $\mathbf{1 0}$ \\
Total & $\mathbf{6}$ & $\mathbf{7}$ & $\mathbf{2 1}$ & $\mathbf{3 4}$ \\
\hline
\end{tabular}

significantly across years (one-way ANOVA, $\mathrm{F}=7.46$, $\mathrm{df}=4, p<0.001$ ). Post hoc comparisons revealed that this difference was due to the large sizes of social units during 2012 (Tukey HSD, $p<0.05$ for all pairwise comparisons including $2012 ; p>0.05$ for all other pairwise comparisons). All social units consisted of adults or a mix of adults and subadults; no social units consisting solely of subadults were detected.

\section{Recaptures of marked animals across years}

A total of 39 individuals (12 males, 27 females) were captured during two or more years of the study (Fig. 2). At first capture, 7 (17.9\%) of these individuals (4 males, 3 females) were subadults; the remaining 32 individuals were adults when first caught (Fig. 2). With one exception, all individuals were recaptured in consecutive years; the exception was a female that was originally captured in 2010 , not recaptured in 2011, but then recaptured in 2012. Most $(61.5 \%, \mathrm{~N}=9$ males, 15 females) of the animals recaptured were trapped during two consecutive field seasons; the remaining individuals (38.5\%, $\mathrm{N}=3$ males, 12 females) were captured during 3 successive field seasons. Of the 15 individuals captured during 3 successive field seasons, $3(20 \%, \mathrm{~N}=2$ males, 1 female) were subadults at first capture.

\section{Spatial consistency of individuals across years}

Of the 39 individuals captured during two or more field seasons, 31 (79.5\%, $\mathrm{N}=7$ males, 24 females) had sufficient spatial data to characterize their home ranges (95\% MCPs) for each year in which they were present in the study population; 20 of these animals (64.5\%, N =6 males, 14 females) were captured during 2 different field seasons while the 


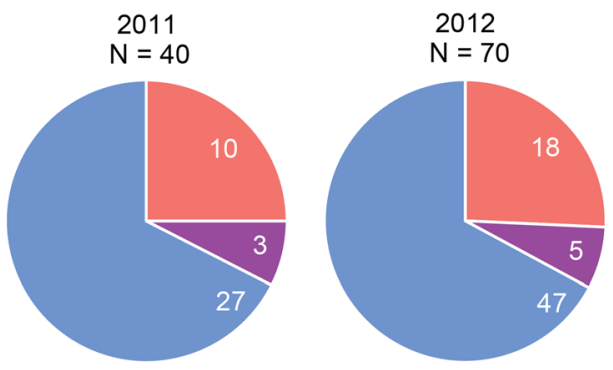

Fig. 2 Proportion of animals in the study population that were recaptured from the previous field season. For each year of the study, the proportion of recaptured animals that had been adults during the previous field season is shown, as is the proportion of recaptured animals that had been subadults during the previous season. Values of $\mathrm{N}$ rep-

remaining $11(35.5 \%, \mathrm{~N}=1$ male, 10 females) were captured during 3 different field seasons (Supplementary Table 2). Comparisons of AIC values revealed that the best fit model for individual home range size included the interaction between sex, age class, and number of years onsite as predictor variables $(\mathrm{AIC}=1159.69, \mathrm{df}=9$; Supplementary Table 3). Number of years on-site was a significant predictor of changes in home range size between years 1 and 2 (Tukey HSD, $p<0.01$ ), with size increasing significantly between an individual's first $\left(721.5 \pm 720.8 \mathrm{~m}^{2}\right)$ and second $\left(1806.6+1573.6 \mathrm{~m}^{2}\right)$ years on the study site (Wilcoxon signed rank, $\mathrm{V}=42, \mathrm{~N}=31, p<0.001)$. In contrast, number of years on-site was not a significant predictor of changes in home range size between years 1 and 3 (Tukey HSD, $p=0.08$ ) or between years 2 and 3 (Tukey HSD, $p=0.91$ ). Accordingly, there were no significant differences in home range size detected between an individual's first and third years or second and third years on the site (Wilcoxon signed rank, both $p>0.05$ ).
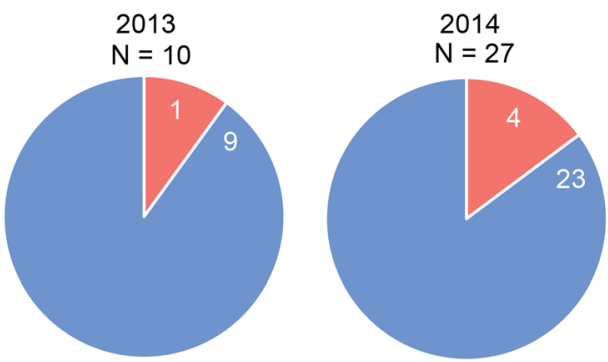

Recaptured adults

Recaptured subadults

New captures resent the total number of animals captured each year; the number of individuals corresponding to each capture category is shown within the associated pie chart. Animals captured in 2010 are described in O’Brien et al. (2020)

Recaptured animals varied markedly with regard to spatial consistency across field seasons, ranging from individuals that displayed no overlap with themselves in successive years ( $\mathrm{N}=1$ male, 9 females) to individuals whose home range during their first year was overlapped completely by their home range during their second year $(\mathrm{N}=2$ males, 2 females; Fig. 3; Supplementary Fig. 2). Comparisons of home ranges from successive years revealed that the mean percent overlap of an individual with itself from year 1 to year 2 was $25.5 \pm 24.3 \%(\mathrm{~N}=31)$. In contrast, mean overlap with other conspecifics in year 2 was $34.2 \pm 30.7 \%$ $(\mathrm{N}=31)$; this tendency to overlap more with other conspecifics was significant (Wilcoxon signed rank, $\mathrm{V}=150$, $p=0.05$ ). For animals captured during three different field seasons $(\mathrm{N}=11)$, mean percent overlap of an individual with itself (year 2 to year 3 ) was $42.1 \pm 22.1 \%$ versus a mean of $34.9 \pm 29.8 \%$ overlap with other conspecifics (year 3); this difference in overlap was not significant (Wilcoxon signed rank, $\mathrm{V}=45$, two-tailed $p=0.32$ ). For individuals captured
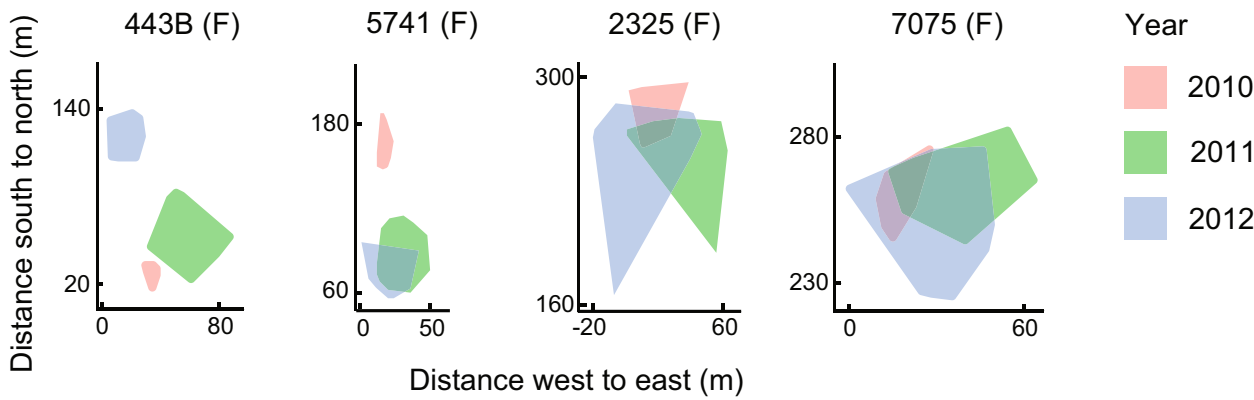

Fig. 3 Patterns of home range overlap across years for a subset of individuals $(\mathrm{N}=4$ females) captured during 3 different field seasons. Animal identity is given above each panel. Colored shapes represent annual home ranges based on $95 \%$ MCPs; year of data collection is

indicated to the right. Axes depict distance in meters; spatial scale differs among the individuals shown. Home ranges for all individuals captured in multiple years are shown in Supplementary Fig. 2 
during three successive field seasons $(\mathrm{N}=11)$, there was a significant tendency for mean percent overlap of an animal with itself from year 1 to year $2(21.6 \pm 23.5 \%)$ to be less than that from year 2 to year $3(42.1 \pm 22.1 \%$; Wilcoxon signed rank, $\mathrm{V}=4, p=0.01)$. Comparison of AIC values revealed that the best fit model for overlap of an individual with itself included sex and age class as predictor variables $(\mathrm{AIC}=284.15, \mathrm{df}=4$; Supplementary Table 3$)$. Age class was a significant predictor of overlap with self $(\mathrm{t}=2.15$, $p=0.04$ ), with individuals first captured as subadults displaying greater overlap $(52.5 \pm 13.6 \% ; \mathrm{N}=6)$ than individuals first captured as adults $(19.0 \pm 21.8 \% ; \mathrm{N}=25)$; because all individuals were adults in year 2 , overlap between years 2 and 3 was not affected by differences in age class.

\section{Social consistency of individuals across years}

Comparisons of social unit sizes for animals captured in successive field seasons revealed that no individuals were solitary for more than 1 year. Of the 6 animals identified as solitary during this study, only $2(33.3 \%)$ were present in the study population for a second year; both of these individuals were assigned to social units containing multiple conspecifics during their second year. No individuals identified as social during their first year were solitary in subsequent years. More generally, of the 31 individuals captured in $\geq 2$ years, most $(58.1 \%, \mathrm{~N}=18)$ lived in larger social units during their second year; in contrast, 9 animals (29.0\%) lived in smaller social units and 4 animals (12.9\%) experienced no change in social unit size from their first to their second year (Supplementary Table 4). This distribution differed significantly from that expected if each of these outcomes (increase, decrease, no change in social unit size) was equally likely ( $X^{2}=9.86, \mathrm{df}=2$, two-tailed $p=0.0072$ ). Of the 11 individuals captured during a third year, almost all $(90.9 \%, \mathrm{~N}=10)$ experienced an increase in social unit size from years 2 to 3 ; social unit size for the eleventh animal did not change.

Comparisons of AIC values revealed that the best fit model for social unit size included sex, age class, and number of years on-site as predictor variables $(\mathrm{AIC}=427.87$, df $=6$; Supplementary Table 3). Number of years on-site was a significant predictor of differences in social unit size between an individual's first and second (Tukey HSD, $p<0.01$ ) and first and third (Tukey HSD, $p<0.01$ ) years on the study site; in contrast, number of years on-site did not predict differences in social unit size between an animal's second and third years on the site (Tukey HSD, $p=0.21$ ). Social unit size increased significantly from year 1 to year 2 $(6.3 \pm 3.1$ versus $11.0 \pm 7.7$ animals/group; Wilcoxon signed rank, $\mathrm{V}=77.5, \mathrm{~N}=31$ individuals, $p=0.007$ ) and from year 1 to year $3(7.0 \pm 3.4$ versus $14.6 \pm 7.2$ animals/group, Wilcoxon signed rank, $\mathrm{V}=4.5, \mathrm{~N}=11$ individuals, $p=0.02$ ).
Analyses of social network metrics indicated that values for eigenvector centrality (Kruskal-Wallis, $X^{2}=7.99$, $\mathrm{df}=2$, $p=0.01$ ), network strength (Kruskal-Wallis, $X^{2}=19.94$, $\mathrm{df}=2, p<0.001$ ), reach (Kruskal-Wallis, $X^{2}=21.14$, $\mathrm{df}=2$, $p<0.001$ ), and affinity (Kruskal-Wallis, $X^{2}=21.37$, $\mathrm{df}=2$, $p<0.001)$ varied significantly with the number of years that an animal was present in the study population (Fig. 4, Supplementary Table 5). In contrast, values for clustering coefficients did not differ with the number of years that an individual was present (Kruskal-Wallis, $X^{2}=1.84, \mathrm{df}=2$, $p=0.40$, Fig. 4, Supplementary Table 5). For each of the four metrics that varied, post hoc Dunn's tests revealed that values were significantly greater for animals during their second year relative to their first year on-site (Table 3). Values for network strength and reach were also significantly greater for animals in their third year relative to their first year on-site (Table 3). All pairwise comparisons of measures of affinity were significant, with values of this metric increasing with each additional year that an animal was present in the population (Table 3 ).

Over the course of the study, we identified 9 instances in which $>2$ animals resident in the same social unit in a given year were recaptured in the following year $(\mathrm{N}=37$ recaptures for 30 animals in 9 social units; Table 4; Supplementary Table 6). In 3 (33.3\%) cases, all animals $(\mathrm{N}=9)$ assigned to the same social unit in year 1 were also assigned to that social unit in year 2 . In the remaining $6(66.6 \%)$ instances, not all animals were resident in the same social unit in year 2 ; in these cases, an average of $60.8 \pm 31.6 \%$ (range $=0.0$ $-85.7 \%$; $N=28$ animals) of individuals assigned to the same social unit in year 1 were still residing in the same social unit in year 2. A total of 9 individuals ( 1 male, 8 females) changed social units between years. These changes occurred even though at least one other individual from an animal's social unit in year 1 was still present in the study population in year 2 , indicating that these changes were not due to the loss of all other members of an individual's initial social unit.

\section{Discussion}

Our analyses revealed intriguing variation in social relationships among members of the study population. Both lone and group-living animals were detected in most years of this study, a pattern that is consistent with species described as facultatively social (Öst et al. 2015; Blumstein et al. 2018; Smith et al. 2018). However, no animals lived alone for more than one field season and no group-living individuals were later detected living alone. Although there was an overall tendency for social unit size to be smaller during an animal's first year on the study site, the magnitude and the direction of between-years changes 
Fig. 4 Social network metrics in relation to total number of years on the study site. Box and whisker plots depict minimum, maximum, median, quartile measures, and outliers of network strength, eigenvector centrality, reach, affinity, and clustering coefficient, as calculated by SOCPROG (Whitehead 2009). For each metric, significant contrasts are indicated with asterisks $(*)$. Measures of network metrics for each individual included in these analyses are presented in Supplementary Table 5
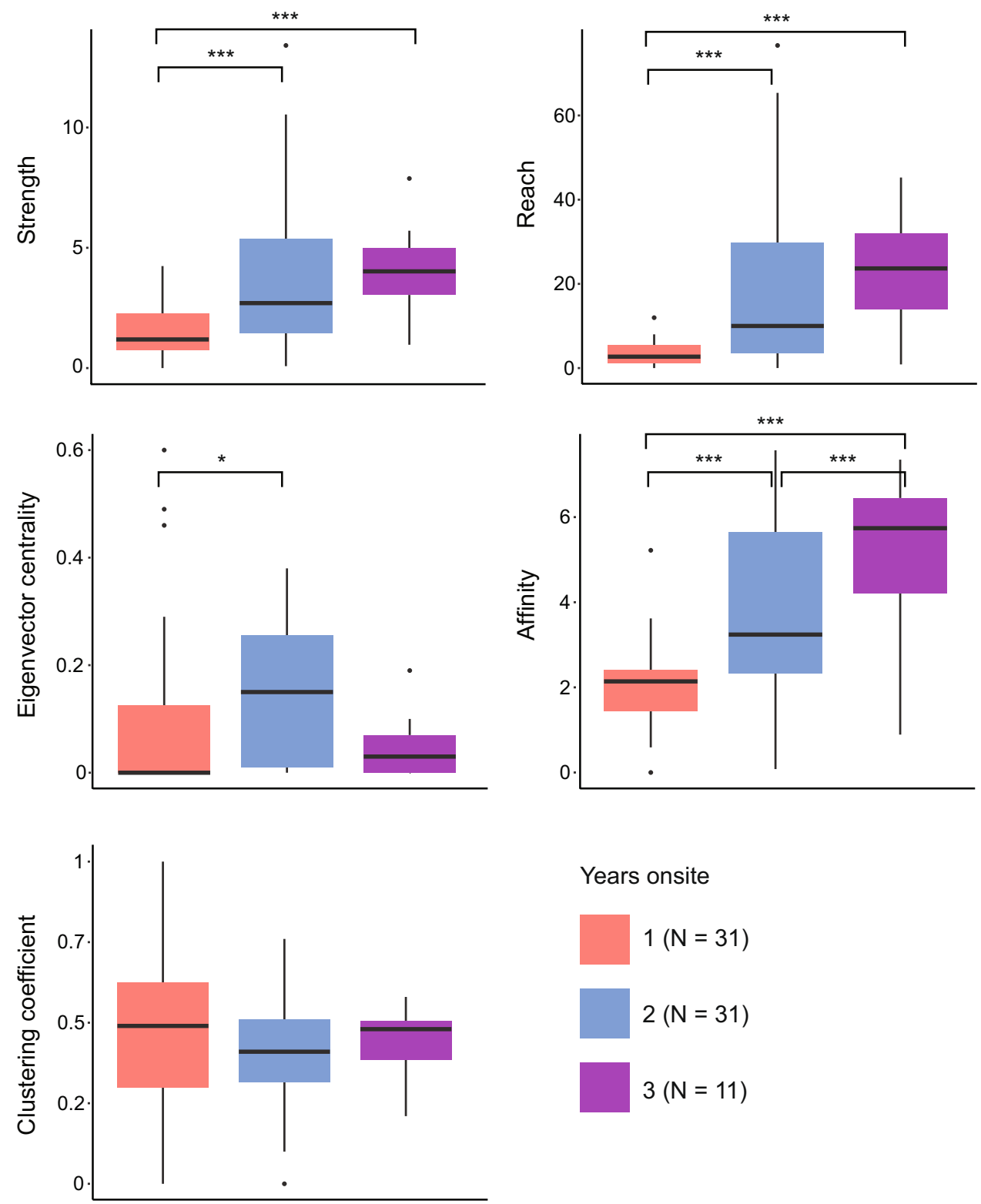

in social unit size varied considerably. Furthermore, while most animals remained in the same social unit (i.e., with the same group mates) in successive years, between-years changes in social unit membership were detected despite the continued presence of at least some of an animal's group mates from the previous field season. Members of the study population also displayed marked variation in individual patterns of space use, notably the tendency to overlap spatially with themselves in successive years. Collectively, these findings suggest that the variation in social relationships reported here is not due to persistent differences in individual behavior but instead may reflect
Table 3 Results of post hoc Dunn's tests for all pairwise comparisons across years for measures of strength, eigenvector centrality, reach, affinity, and clustering coefficient

\begin{tabular}{llllll}
\hline Years & Strength & Eigenvector centrality & Reach & Affinity & Clustering coefficient \\
\hline $1-2$ & $\mathbf{Z}=\mathbf{- 3 . 6 2}$ & $\mathbf{Z}=\mathbf{- 2 . 6 0}$ & $\mathbf{Z}=\mathbf{- 3 . 4 8}$ & $\mathbf{Z}=\mathbf{- 3 . 3 6}$ & $\mathrm{Z}=1.35$ \\
& $\boldsymbol{p}<\mathbf{0 . 0 0 1}$ & $\boldsymbol{p}=\mathbf{0 . 0 2}$ & $\boldsymbol{p}=\mathbf{0 . 0 0 1}$ & $\boldsymbol{p}<\mathbf{0 . 0 0 1}$ & $p=0.53$ \\
$1-3$ & $\mathbf{Z}=\mathbf{- 3 . 7 5}$ & $\mathrm{Z}=0.09$ & $\mathbf{Z}=\mathbf{- 4 . 0 6}$ & $\mathbf{Z}=\mathbf{- 4 . 1 7}$ & $\mathrm{Z}=0.34$ \\
& $\boldsymbol{p}<\mathbf{0 . 0 0 1}$ & $p=0.92$ & $\boldsymbol{p}<\mathbf{0 . 0 0 1}$ & $\boldsymbol{p}<\mathbf{0 . 0 0 1}$ & $p=0.73$ \\
$2-3$ & $\mathrm{Z}=-1.14$ & $\mathrm{Z}=1.98$ & $\mathrm{Z}=-1.54$ & $\mathbf{Z}=\mathbf{1 . 7 5}$ & $\mathrm{Z}=-0.63$ \\
& $p=0.26$ & $p=0.10$ & $p=0.12$ & $\boldsymbol{p}<\mathbf{0 . 0 0 1}$ & $p=1.00$ \\
\hline
\end{tabular}

Significant results are in bold 
Table 4 Proportion of animals remaining in the same social unit in successive years. For each entry, the numerator indicates the number of animals assigned to the same social unit in years 1 and 2; the denominator indicates the number of animals captured in year 1 (members of the same social unit) that were recaptured in year 2 . Data for 9 distinct social units are shown. No animals were recaptured together from 2012 to 2013, and thus that pair of years is marked as N/A. The identities of specific pairs of individuals captured together in successive years are given in Supplementary Table 6

\begin{tabular}{llll}
\hline \multicolumn{4}{l}{ Successive years captured } \\
\hline $2010-2011$ & $2011-2012$ & $2012-2013$ & $2013-2014$ \\
\hline $4 / 4$ & $3 / 3$ & N/A & $0 / 3$ \\
$2 / 2$ & $3 / 5$ & - & - \\
$2 / 3$ & $6 / 7$ & - & - \\
- & $6 / 7$ & - & - \\
- & $2 / 3$ & - & - \\
\hline
\end{tabular}

short-term responses to variation in factors such as ecological or demographic conditions.

\section{Variation in spatial relationships}

Our analyses of social relationships were based on spatial data; and thus, examining patterns of space use by members of the study population may generate insights into the variability in social behavior reported here. Among animals captured in successive years, the tendency to remain residents at the same location varied, with between-years spatial overlap of an individual with itself ranging from none to almost complete congruence of annual home ranges. Overall, overlap tended to be greater between an individual's second and third years on the study site, suggesting that animals became more spatially consistent over time. Individuals first captured as subadults overlapped more with themselves than did animals first captured as adults, indicating that age may contribute to individual patterns of space use (Rayor and Armitage 1991; Salvioni and Lidicker 1995; Ortiz et al. 2019). Variation in between-years overlap may also reflect differences in dispersal history (Murray 1982; Nelson and Mech 1984; Costello 2010). For example, it is possible that animals first captured as subadults were individuals that had been born on the study site after the previous field season; in contrast, animals first captured as adults may have immigrated to the site. These differences in age and/or dispersal history may have contributed to variation in the location, size, or quality of individual home ranges during an animal's first year in the study population (Dahle et al. 2006; Saïd et al. 2009); and this variation may, in turn, have affected the tendency for an individual to shift its location over time. Dispersal patterns in C. opimus are not well understood and additional studies that monitor individuals throughout the year are required to evaluate the potential effects of age and dispersal history on temporal patterns of space use within the study population.

\section{Variation in social relationships}

Social relationships - as measured by social unit sizevaried at both the population and individual levels. Within years, social units ranged from one to up to two dozen individuals. This variation was evident during four of the five years of this study, indicating that a mix of lone and groupliving animals was a persistent feature of the study population. Although sample size was limited, no individuals lived alone for more than one field season; this observation, in conjunction with the overall spatial and social variability detected, suggests that living alone was not a consistent behavioral tendency among some members of the study population. At present, however, phenotypic or other predictors of living alone remain unknown. All lone animals were adults, providing no evidence that age contributed to the occurrence of this social outcome. Each of these individuals was living alone during the first field season in which it was captured, raising the possibility that lone animals were immigrants to the study population. However, other animals captured for the first time were group-living, making it difficult to evaluate the effects of demographic history on an individual's social environment. As noted above, future studies that provide more detailed information regarding individual patterns of movement should help to clarify the factors underlying variability in social relationships.

Among animals captured in successive years, annual changes in social unit size varied markedly, although there was an overall tendency for social unit size to increase with time. More specifically, number of years on the site was a significant predictor of social unit size, with number of group mates in year 1 being significantly less than that in years 2 or 3. Consistent with this, animals that initially lived alone were group-living during their second year on the site. Furthermore, values for most social network metrics examined were significantly greater for animals present in the study population for 2 or 3 years, suggesting that the strength of social associations increased over time. Although the number of years on the site was not a direct measure of age, these outcomes suggest that individuals tended to associate with more conspecifics as they grew older. In general, individuals were assigned to the same social unit in successive years, raising the possibility of enduring relationships among specific members of the study population. For individuals that changed social units, the factors contributing to those changes remain unknown. Future studies that explore interactions between social unit size and composition in greater detail should help clarify the reasons for the 
variability in social relationships reported here (Ebensperger et al. 2009).

\section{Characterizing facultative sociality}

The persistent occurrence of lone and group-living animals in the study population suggests that $C$. opimus can be described as facultatively social, as originally proposed by O'Brien et al. (2020) based on data from a single season of research at Pozuelos. Intraspecific variability in spatial and social relationships can generate important insights into the adaptive bases for these aspects of behavior and comparative analyses of facultatively social taxa should facilitate such efforts (Rubenstein and Abbot 2017). Such comparisons are challenging, however, due to the lack of a consistent definition for facultative sociality. While some authors view the cooccurrence of lone and group-living conspecifics as part of an evolutionary transition toward obligate sociality (Rehan et al. 2010; Shell and Rehan 2018), others interpret such variation as differences in adaptive responses to current environmental conditions (Rabosky et al. 2012; Ortiz et al. 2019). The latter perspective assumes that individuals adjust their behavior to reflect the fitness consequences of living alone versus within a group (Lacey 2004; Ebensperger et al. 2012); this assumption is critical to distinguishing adaptive variation in behavior from differences that arise due to more stochastic factors such as mortality of group mates. Relative fitness has not yet been assessed for lone versus group-living C. opimus, and thus we cannot exclude the possibility that the observed variation in social unit size reflects random changes within the study population. However, the pronounced between-years differences in behavior detected for some individuals (e.g., no overlap of annual home ranges) as well as the tendency for some animals to change social units despite the continued presence of previous group mates suggest that temporal variation in spatial and social relationships is not simply a consequence of stochastic changes in the composition of the study population.

\section{Implications for social organization}

In facultatively social populations, variation in social behavior may arise due to persistent differences in individual behavior that lead some animals to consistently live alone while others consistently occur in groups (Krause et al. 2010; Wilson et al. 2013). Alternatively, animals may live alone versus in groups due to variability in the fitness consequences associated with these behavioral options (McGuire et al. 2002; Silk 2007; Woodruff et al. 2013). Distinguishing between these sources of behavioral variation is critical to evaluating the adaptive bases for population-level differences in social relationships. The fitness outcomes of behavior are influenced by current ecological and demographic conditions (Silk 2007; Rehan et al. 2011; Blumstein
2013), as well as by differences in individual phenotypes (Öst et al. 2015; Ferree et al. 2018). Each of these parameters may change over time, resulting in a dynamic suite of variables that can impact the adaptive bases for living alone versus within a group and, hence, the social organization of the population. As a result, understanding how ecological, demographic, and phenotypic differences interact to shape the behavior of individuals can generate critical insights into larger patterns of social behavior. We found no evidence that the tendency for members of our study population to live alone versus in groups occurred due to persistent differences in individual behavior. Instead, we suggest that the observed variability in spatial and social relationships reflects differences in adaptive responses to immediate ecological and demographic conditions. To test this hypothesis, we recommend that future studies of $C$. opimus include more detailed information regarding individual demographic histories as well as quantitative assessments of critical ecological parameters such as food resources and population density. These data, in conjunction with long-term monitoring of individual behavior, should substantially improve our understanding of the adaptive bases for facultative differences in social organization in this and other group-living species of animals.

Supplementary Information The online version contains supplementary material available at https://doi.org/10.1007/s00265-021-03034-z.

Acknowledgements For permits: Delegacion Técnica NOA de Parques Nacionales, particularly Maria Elena Sanchez and Juliana de Gracia. For housing and logistic support: the Intendente and guards at Monumento Natural Laguna de los Pozuelos, in particular Cristian Mamani, Walter Arias, Marcos Bernuci, and Sergio Ariel Carzon. Field assistants: D. Rodriguez, J. Wieczorek, B. Sousa, J. Woodruff, A. Geraghty, and Uma the boxer. Thank you to Michelle St. John for advice regarding the statistical analyses and to two anonymous reviewers whose comments substantially improved the manuscript.

Funding Funding for this research was provided by the Museum of Vertebrate Zoology.

Data availability Datasets analyzed in this study are available in Supplementary Table 1.

\section{Declarations}

Ethics approval All procedures were approved by the Animal Care and Use Committee at the University of California, Berkeley, and were consistent with guidelines established by the American Society of Mammalogists for the use of wild mammals in research (Sikes et al. 2016).

Conflict of interest The authors declare no competing interests.

Open Access This article is licensed under a Creative Commons Attribution 4.0 International License, which permits use, sharing, adaptation, distribution and reproduction in any medium or format, as long as you give appropriate credit to the original author(s) and the source, 
provide a link to the Creative Commons licence, and indicate if changes were made. The images or other third party material in this article are included in the article's Creative Commons licence, unless indicated otherwise in a credit line to the material. If material is not included in the article's Creative Commons licence and your intended use is not permitted by statutory regulation or exceeds the permitted use, you will need to obtain permission directly from the copyright holder. To view a copy of this licence, visit http://creativecommons.org/licenses/by/4.0/.

\section{References}

Altmann J (1974) Observational study of behavior: sampling methods. Behaviour 49:227-266

Blumstein DT (2013) Yellow-bellied marmots: insights from an emergent view of sociality. Phil Trans R Soc B 368:20120349

Blumstein DT, Williams DM, Lim A, Kroeger S, Martin JG (2018) Strong social relationships are associated with decreased longevity in a facultatively social mammal. Proc R Soc B 285:20171934

Bridge PD (1993) Classification. In: Fry JC (ed) Biological data analysis. Oxford University Press, Oxford, pp 219-242

Cahan S, Carloni E, Liebig J, Pen I, Wimmer B (1999) Causes and consequences of sociality. Ethol Ecol Evol 11:85-87

Calenge $\mathrm{C}$ (2015) Home range estimation in $\mathrm{R}$ : the adehabitatHR package, https://cran.r-project.org/web/packages/adehabitatHR/ vignettes/adehabitatHR.pdf

Costello CM (2010) Estimates of dispersal and home-range fidelity in American black bears. J Mamm 91:116-121

Dahle B, Støen OG, Swenson JE (2006) Factors influencing homerange size in subadult brown bears. J Mammal 87:859-865

Eason P (2010) Alarm signaling in a facultatively social mammal, the southern Amazon red squirrel Sciurus spadiceus. Mammalia 74:343-345

Ebensperger LA, Hurtado MJ, Soto-Gamboa M, Lacey EA, Chang AT (2004) Communal nesting and kinship in degus (Octodon degus). Naturwissenschaften 91:391-395

Ebensperger LA, Chesh AS, Castro RA, Tolhuysen LO, Quirici V, Burger JR, Hayes LD (2009) Instability rules social groups in the communal breeder rodent Octodon degus. Ethology 115:540-554

Ebensperger LA, Rivera DS, Hayes LD (2012) Direct fitness of group living mammals varies with breeding strategy, climate and fitness estimates. J Anim Ecol 81:1013-1023

Ferree E, Johnson S, Barraza D, Crabo E, Florio J, Godtfredsen H, Holland K, Jitmana K, Mark K (2018) Size-dependent variability in the formation and trade-offs of facultative aggregations in golden orb-web spiders (Nephila clavipes). Behav Ecol Sociobiol 72:157

Harris S, Cresswell WJ, Forde PG, Trewhella WJ, Woollard T, Wray S (1990) Home-range analysis using radio-tracking data-a review of problems and techniques particularly as applied to the study of mammals. Mammal Rev 20:97-123

Hatchwell BJ, Sharp SP, Beckerman AP, Meade J (2013) Ecological and demographic correlates of helping behaviour in a cooperatively breeding bird. J Animal Ecol 82:486-494

Hayes LD, Solomon NG (2004) Costs and benefits of communal rearing to female prairie voles (Microtus ochrogaster). Behav Ecol Sociobiol 56:585-593

Krause J, Lusseau D, James R (2009) Animal social networks: an introduction. Behav Ecol Sociobiol 63:967-973

Krause J, James R, Croft DP (2010) Personality in the context of social networks. Phil Trans R Soc B 365:4099-4106

Lacey EA (2004) Sociality reduces individual direct fitness in a communally breeding rodent, the colonial tuco-tuco (Ctenomys sociabilis). Behav Ecol Sociobiol 56:449-457
Lacey EA, Braude SH, Wieczorek JR (1997) Burrow sharing by colonial tuco-tucos (Ctenomys sociabilis). J Mammal 78:556-562

Le Roux A, Cherry MI, Manser MB (2009) The vocal repertoire in a solitary foraging carnivore, Cynictis penicillata, may reflect facultative sociality. Naturwissenschaften 96:575-584

Lott DF (1984) Intraspecific variation in the social systems of wild vertebrates. Behaviour 88:266-325

Lott DF (1991) Intraspecific variation in the social systems of wild vertebrates, vol 2. Cambridge University Press, Cambridge

May-Itzá WDJ, Medina LM, Medina S, Paxton RJ, Quezada-Euán JJG (2014) Seasonal nest characteristics of a facultatively social orchid bee, Euglossa viridissima, in the Yucatan Peninsula, Mexico. Insect Soc 61:183-190

McGuire B, Getz LL, Oli MK (2002) Fitness consequences of sociality in prairie voles, Microtus ochrogaster: influence of group size and composition. Anim Behav 64:645-654

Murray MG (1982) Home range, dispersal and the clan system of impala. Afr J Ecol 20:253-269

Nelson ME, Mech LD (1984) Home-range formation and dispersal of deer in northeastern Minnesota. J Mammal 65:567-575

Newman ME (2006) Modularity and community structure in networks. P Natl Acad Sci USA 103:8577-8582

O'Brien SL, Tammone MN, Cuello PA, Lacey EA (2020) Facultative sociality in a subterranean rodent, the highland tuco-tuco (Ctenomys opimus). Biol J Linn Soc 129:918-930

Ortiz CA, Pendleton EL, Newcomb KL, Smith JE (2019) Conspecific presence and microhabitat features influence foraging decisions across ontogeny in a facultatively social mammal. Behav Ecol Sociobiol 73:42

Öst M, Seltmann MW, Jaatinen K (2015) Personality, body condition and breeding experience drive sociality in a facultatively social bird. Anim Behav 100:166-173

Patton JL, Pardiñas UF, Delía G (2015) Mammals of South America, vol 2 rodents. University of Chicago Press, Chicago

R Core Team (2013) R: a language and environment for statistical computing. R Foundation for Statistical Computing, Vienna, Austria, http://www.R-project.org/

Rabosky ARD, Corl A, Liwanag HE, Surget-Groba Y, Sinervo B (2012) Direct fitness correlates and thermal consequences of facultative aggregation in a desert lizard. PLoS ONE 7:e40866

Rayor LS, Armitage KB (1991) Social behavior and space-use of young of ground-dwelling squirrel species with different levels of sociality. Ethol Ecol Evol 3:185-205

Rehan SM, Richards MH, Schwarz MP (2010) Social polymorphism in the Australian small carpenter bee, Ceratina (Neoceratina) australensis. Insect Soc 57:403-412

Rehan SM, Schwarz MP, Richards MH (2011) Fitness consequences of ecological constraints and implications for the evolution of sociality in an incipiently social bee. Biol J Linn Soc 103:57-67

Rehan SM, Richards MH, Adams M, Schwarz MP (2014) The costs and benefits of sociality in a facultatively social bee. Anim Behav 97:77-85

Riley JL, Küchler A, Damasio T, Noble DW, Byrne RW, Whiting MJ (2018) Learning ability is unaffected by isolation rearing in a family-living lizard. Behav Ecol Sociobiol 72:20

Rubenstein DR, Abbot P (2017) Comparative social evolution. Cambridge University Press, Cambridge

Saïd S, Gaillard JM, Widmer O, Débias F, Bourgoin G, Delorme D, Roux C (2009) What shapes intra-specific variation in home range size? A case study of female roe deer. Oikos 118:1299-1306

Salvioni M, Lidicker WZ (1995) Social organization and space use in California voles: seasonal, sexual, and age-specific strategies. Oecologia 101:426-438 
Shell WA, Rehan SM (2017) The price of insurance: costs and benefits of worker production in a facultatively social bee. Behav Ecol 29:204-211

Shell WA, Rehan SM (2018) Behavioral and genetic mechanisms of social evolution: insights from incipiently and facultatively social bees. Apidologie 49:13-30

Sikes RS, Animal Care and Use Committee of the American Society of Mammalogists (2016) 2016 Guidelines of the American Society of Mammalogists for the use of wild mammals in research and education. J Mammal 97:663-688

Silk JB (2007) The adaptive value of sociality in mammalian groups. Phil Trans R Soc B 362(1480):539-559

Smith JE, Long DJ, Russell ID, Newcomb KL, Muñoz VD (2016) Otospermophilus beecheyi (Rodentia: Sciuridae). Mammal Spec 48:91-108

Smith A, Harper C, Kapheim K, Simons M, Kingwell C, Wcislo W (2018) Effects of social organization and resource availability on brood parasitism in the facultatively social nocturnal bee Megalopta genalis. Insect Soc 65:85-93

Sobrero R, Prieto AL, Ebensperger LA (2014) Activity, overlap of range areas, and sharing of resting locations in the moon-toothed degu, Octodon lunatus. J Mammal 95:91-98
Soria M, Fréon P, Chabanet P (2007) Schooling properties of an obligate and a facultative fish species. J Fish Biol 71:1257-1269

Wey T, Blumstein DT, Shen W, Jordan F (2008) Social network analysis of animal behaviour: a promising tool for the study of sociality. Anim Behav 75:333-344

Whitehead H (2008) Analyzing animal societies: quantitative methods for vertebrate social analysis. University of Chicago Press, Chicago

Whitehead H (2009) SOCPROG programs: analyzing animal social structures. Behav Ecol Sociobiol 63:765-778

Wilson AD, Krause S, Dingemanse NJ, Krause J (2013) Network position: a key component in the characterization of social personality types. Behav Ecol Sociobiol 67:163-173

Woodruff JA, Lacey EA, Bentley GE, Kriegsfeld LJ (2013) Effects of social environment on baseline glucocorticoid levels in a communally breeding rodent, the colonial tuco-tuco (Ctenomys sociabilis). Horm Behav 64:566-572

Publisher's note Springer Nature remains neutral with regard to jurisdictional claims in published maps and institutional affiliations. 